\title{
On positive shifting baselines and the importance of optimism
}

\section{A N D REW B A LMFORD}

Early morning at The Royal Society for the Protection of Birds' Ham Wall reserve, in Somerset, UK. On passing an even earlier visitor, the natural history writer and broadcaster Stephen Moss poses the birdwatcher's perennial question: 'Seen anything?.' 'Nothing much', comes the reply 'just the usual'. But here in the heart of the Avalon Marshes-one of the largest expanses of restored wetland in the UK-what now passes as usual is anything but.

Before being drained for farming and mined for peat, a complex mosaic of raised bog, reed-bed and fen woodland once blanketed the valley between the Mendips and the Polden Hills. By the mid 1800 s little natural habitat remained, and following World War II, agricultural intensification and industrialized peat extraction for horticulture reduced wildlife populations still further. But by the 1990s growing public concern about the environmental impact of peat removal led to the scaling-back of operations and catalysed a remarkable partnership between English Nature (now Natural England), The Royal Society for the Protection of Birds, the Somerset Wildlife Trust, the Hawk and Owl Trust, and remaining small-scale peat firms. Exhausted peat diggings were returned to nature, and water levels raised: near-vanished habitats were restored at landscape scale.

Recreated wetland now stretches in an unbroken $\operatorname{arc} 7 \mathrm{~km}$ long (modest, perhaps, by global standards but immense for southern England). Rare orchids, otters and great silver water beetles have returned. The overwintering starling population can number up to 1 million, and the marshes have become the first point of colonization for several heron species expanding their ranges northwards under climate change. On an otherwise unexceptional summer morning 'the usual' inhabitants of Avalon include 45 booming male bitterns (compared with just 11 nationwide in 1997), nine nesting marsh harriers (1970 UK population: two birds), and seven great white egrets (a species that only began breeding in Britain in 2012).

Of course this story stands in marked contrast to the great bulk of the news in conservation. The recently published State of Nature 2016 report suggests that across the $\mathrm{UK}$ as a whole the mean abundance and occupancy of 2,500 reasonably well-tracked species has fallen by $16 \%$ since 1970 (Hayhow et al., 2016). Globally, the latest Living Planet Index reckons 14,000 monitored vertebrate populations shrank by an average of $58 \%$ over the same period (WWF, 2016). New data show the already Endangered

ANDREW BALMFord Department of Zoology, University of Cambridge, Cambridge, UK. E-mail apb12@cam.ac.uk
Grauer's gorilla declined by a further $80 \%$ in the past 20 years (and is now Critically Endangered; Plumptre et al., 2016), and the death on 16 September 2016 of the last surviving captive Rabbs' fringe-limbed tree frog almost certainly marked the extinction of the species.

Yet the return of Avalon is not an isolated example (Balmford, 2012). In the largely converted Atlantic forest landscapes of Rio de Janeiro State in Brazil, for instance, retention of remaining, privately owned fragments and restoration of key corridors has helped the wild population of the Endangered golden lion tamarin grow from 200 to more than 3,200 individuals in three decades (AMLD, 2016). In the past year the giant panda has been downlisted from Endangered to Vulnerable based on the expansion of its habitat (Swaisgood et al., 2016). In spite of much uncertainty elsewhere in the European Union, 2016 also saw the EU-on the back of over half a million submissions by concerned citizens and businesses-decide not to open up its powerful Birds and Habitats \& Species Directives for 'revision'; in the current climate of deregulation, this was a signal victory for conservation. Clearly people can and do make a difference.

This issue of Oryx highlights several more stories of hope: good news about Hippopotamus amphibius in Cameroon (Scholte et al., 2017); progress in easing conflict between H. amphibius and rice farmers in Guinea-Bissau (González et al., 2017); Zimbabwean prosecutors taking a tough stand against illegal pangolin traders (Shepherd et al., 2017); and evidence of freshwater protected areas helping to rebuild fish stocks in the Amazon (Keppeler et al., 2017).

Reasons to be cheerful rather than despondent are also at the forefront of \#EarthOptimism, a global initiative designed to move the conservation conversation away from doom and gloom, which will be celebrated with a major series of public events centred around Earth Day, 22 April 2017. Simultaneous events in Washington, Cambridge, London, Dallas and elsewhere will concentrate on solutions rather than problems, and flag the importance of well-informed optimism in motivating enduring change in our relationships with nature. To take part in an \#EarthOptimism event in person or online, visit http://earthoptimism.si. edu/ or www.cambridge conservation.org/earthoptimism/.

In some cases the conservation movement's successes are starting to alter what we think of as normal. Our baselines are shifting. In most countries it is now difficult to imagine women being denied the vote, or smoking in restaurants or offices becoming acceptable once more (Pauly, 2011). So too in conservation. In much of Britain birdwatchers have become almost blasé about seeing red kites (down to fewer 
than 20 pairs in the 1960s) tilting over towns and roadsides. Ospreys are once again considered common in coastal North America. The bitterns (and indeed glossy ibises) of the Avalon Marshes have become 'the usual'. Much of me rejoices at this recalibration. These creatures should be part of our expectations. Healthy populations of raptors, strong laws to protect nature, and reed-beds that stretch to the horizon should be unremarkable: the rule, rather than the exception.

But I also have a worry here-one that underscores the importance of consciously and continually reminding ourselves of conservation's achievements. Just as negative shifting baselines-repeated acts of intergenerational amnesia over nature's erosion-mean we have often failed to grasp the scale of human-driven declines (Pauly, 1995), so positive shifting baselines also carry a risk. If we fail to remember and to celebrate what conservation has achieved, we miss opportunities to convince the public that there are real and practical solutions with which they can engage. We lessen the chances of learning from our successes. If we forget where we've come from, we risk allowing things to slip backwards.

In the UK the partial recovery of the common buzzard is now seen as sufficient for the government to sanction the return of its lethal control 'to prevent serious damage to young pheasants' (Natural England, 2016). But this argument ignores the role buzzards play in limiting numbers of corvids (whose populations have been boosted by roadkills and that through nest predation probably suppress declining songbirds; Lees et al., 2013); it overlooks the fact that buzzards and many rarer raptors are still illegally persecuted in much of the country; and it neglects the point that all this is to protect the economic interests of a shooting industry that releases over 50 million alien game birds into the countryside each year. Likewise in the USA the nascent recovery of wolf populations has prompted some elements of the hunting community to persuade several states to delist wolves as endangered (Refsnider, 2009), even though their current population (outside Alaska) is probably less than $2 \%$ of historic levels. Similar sentiments underpinned those calls to 'revise' the EU's conservation Directives, despite evidence they are successfully slowing continued declines in European biodiversity (Sanderson et al., 2016). If as a result of positive shifting baselines we fail to remind ourselves and others of where we would be without conservation, the progress we have made risks being reversed.

While there is as great a need as ever for us to track changes in the natural world, detect and communicate new threats, and devise interventions to address them, celebrating conservation's many and diverse accomplishments is also vital: to inspire people rendered hopeless by what can seem like an unending torrent of bad news, and motivate them to purposeful action; to learn more about what works-and hence be able to sharpen our efforts; and so that we can reinforce rather than let drift the many gains that the conservation movement is making.

\section{Acknowledgements}

I am very grateful to Stephen Moss for sharing his Ham Wall anecdote, Steve Hughes and Malcolm Ausden for data on Avalon Marshes, Luís Paulo Ferraz for information on golden lion tamarins, Rhys Green and Martin Harper for discussing buzzards, and Nancy Knowlton for inventing \#EarthOptimism.

\section{References}

AMLd (Associação Mico-Leão-Dourado) (2016) História da proteção does micos-leões-dourados. www.micoleao.org.br/ [accessed 23 December 2016].

B Almford, A. (2012) Wild Hope: On the Frontlines of Conservation Success. Chicago University Press, Chicago, USA.

Gonzalez, L., Montoto, F.G.D., Mereck, T. \& Alves, J. (2017) Preventing crop raiding by the Vulnerable common hippopotamus Hippopotamus amphibius in Guinea-Bissau. Oryx, 51, 222-229.

Haynow, D.B., Burns, F., Eaton, M.A., Al Fulai,, N., August, T.A., BABEY, L. et al. (2016) State of Nature 2016. State of Nature Partnership, UK.

Keppeler., F.W., Hallwass, G. \& Matias Silvano, R.A. (2017) Influence of protected areas on fish assemblages and fisheries in a large tropical river. Oryx, 51, 268-279.

Lees, A.C., Newton, I. \& Balmford, A. (2013) Pheasants, buzzards and trophic cascades. Conservation Letters, 6, 141-144.

Natural England (2016) Licence for Buzzard Control. www.gov.uk/ government/news/licence-for-buzzard-control [accessed 14 December 2016].

PAUly, D. (1995) Anecdotes and the shifting baseline syndrome of fisheries. Trends in Ecology and Evolution, 10, 430.

PaUly, D. (2011) On baselines that need shifting. Solutions, 2, 14. Plumptre, A.J., Nixon, S., Kuijirakwinja, D.K., Vieilledent, G., Critchlow, R., Williamson, E.A. et al. (2016) Catastrophic decline of the world's largest primate: $80 \%$ loss of Grauer's gorilla (Gorilla beringei graueri) population justifies Critically Endangered status. PLoS ONE, 11(10), e0162697.

Refsnider, R.L. (2009) The role of the Endangered Species Act in Midwest wolf recovery. In Recovery of Gray Wolves in the Great Lakes Region of the United States (eds E. Heske, T.R. Deelen \& A. P. Wydeven), pp. 311-329. Springer, New York, USA.

Sanderson, F.J., Pople, R.G., Ieronymidou, C., Burfield, I.J., Gregory, R.D., Willis., S.G. et al. (2016) Assessing the performance of EU nature legislation in protecting target bird species in an era of climate change. Conservation Letters, 9, 172-180.

Scholte, P., Nguimkeng, F. \& Iyah, E. (2017) Good news from north-central Africa: largest population of Vulnerable common hippopotamus Hippopotamus amphibius is stable. Oryx, 51, 218-221.

Shepherd, C.R., E. Connelly, L. Hywood \& P. Cassey (2017) Taking a stand against illegal wildlife trade: the Zimbabwean approach to pangolin conservation. Oryx, 51, 280-285.

Swaisgood, R., Wang, D. \& Wei, F. (2016) Ailuropoda melanoleuca. The IUCN Red List of Threatened Species 2016: e.T712A 45033386. Http://dx.doi.org/10.2305/IUCN.UK.2016-2.RLTS.T712A45033386. en [accessed 14 December 2016].

WWF (2016) Living Planet Report 2016. Risk and Resilience in a New Era. WWF International, Gland, Switzerland. 